\title{
Improving Magnetic Gear Overload Torque with Cage Rotor Bars
}

\author{
Yusuf Akcay, Tom Cox, Alessandro Costabeber \\ Dept. of Electrical and Electronics Engineering, Univ. of Nottingham, United Kingdom, \\ yusuf.akcay@nottingham.ac.uk.
}

\begin{abstract}
This paper introduces a coaxial magnetic gearbox with a new high-speed rotor configuration. The proposed configuration optimizes magnet volume and employs cage rotor bars in the high-speed rotor. The resulting proposed gear improves torque performance at overload condition, and utilises $5 \%$ less magnet volume in the highspeed rotor.
\end{abstract}

Index Terms - Cage bar, magnetic gear, permanent magnet.

\section{INTRODUCTION}

Mechanical gearboxes are employed in industries for different speed, torque and position demands. They are widely operated with high speed electrical machines to improve torque density and to be cost-effective [1]. Although it is very common to employ mechanical gearboxes, they bring some problems such as backlash, vibration, maintenance and noise [2]. To overcome these problems, magnetic gearboxes have been considered for decades [3]. Magnetic gearboxes have many advantages including contactless torque transmission, reduced maintenance requirements and inherent overload protection [4]. Early attempts were not popular, mainly because of low torque density [5]. The topology introduced in [6] attracted researchers because of its high torque density compared with other magnetic gearboxes and mechanical counterparts. In electrical machines, to increase the produced torque per volume, it is necessary to increase magnetic flux density in the airgap. One option is to increase the airgap flux by increasing magnet volume [7]. However, unlike electrical machines, it is important not only to consider the main flux but also to consider modulated flux which plays important role in production of high torque in magnetic gearboxes. Therefore, an increase in magnet span may not give a proportionate increase in the modulated field as some of the flux does not pass the airgap and so does not contribute to modulated flux.

The purpose of this paper is to introduce a new highspeed rotor configuration for a coaxial magnetic gearbox. The proposed gearbox optimizes magnet volume and employs cage rotor bars, integrated into the high-speed rotor as shown in Fig. 1. The resulting proposed gearbox aims to reduce magnet volume without reducing the performance of the MG, and gives better torque production in overload conditions. The objectives of the paper are to analyze the modulated flux as a function of the magnetspan on the high-speed rotor and to observe the torque contribution of the cage rotor bars in overload conditions.
The results are then compared with a conventional magnetic gearbox.

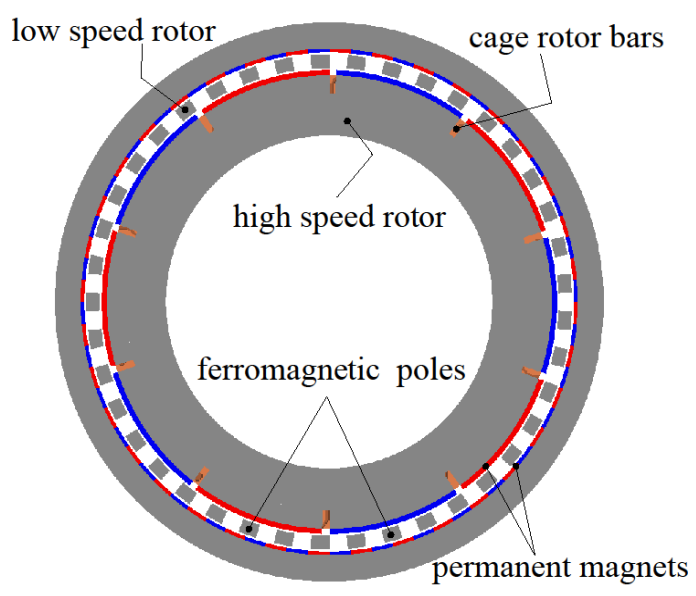

Fig. 1. Proposed magnetic gearbox

\section{THE OPERATIONAL PRINCIPLE OF MAGNETIC GEARBOX}

The gearbox consists of three circumferential parts; outer magnetic pole-pieces, ferromagnetic pole pieces and an inner high-speed rotor. Torque production in the magnetic gearbox relies on the flux modulation principle. The magnetic flux produced by the high-speed rotor is modulated by ferromagnetic pole pieces, developing a harmonic at the same pole number and pitch as that of the low speed rotor. The two fields interact to produce torque. As a result of modulation, the gearbox can modify a low torque high speed input into a high torque lower speed output [8].

In order to transmit a stable torque as a gearbox, the number of pole-pairs in the harmonic component of modulated flux must be equal to the number of pole pairs in the inner rotor. Therefore, the number of magnet pole pairs and the number of ferromagnetic pole pieces become

$$
Q=p_{i}+p_{O}
$$

where $Q, p_{i}$ and $p_{O}$ are the number of ferromagnetic pole pieces, the number of pole pairs in the inner rotor and the number of pole pairs on the outer magnet array respectively. The gear ratio for the proposed gearbox is given by:

$$
G=\frac{Q}{p_{i}}
$$


The flux density distribution and torque production can be explained by using Laplace and Poisson's equations of magnetic vector potential in the magnet and the airgap subdomains [10]- [11]. The radial and tangential components of the flux density distribution in the airgap due to either pole pairs are detailed in [6] and [10]- [11].

\section{Proposed DESIGN}

The proposed magnetic gear is shown in Fig.1. The parameters of the proposed gearbox are given in Table I. These parameters are used in the conventional gearbox for comparison with the proposed gearbox.

TABLE I: Parameters of the magnetic gearbox.

\begin{tabular}{ll}
\hline Pole-pairs on high speed rotor, & 5 \\
Pole pairs on stationary outer part, & 36 \\
Number of ferromagnetic pole pieces, $q$ & 41 \\
Gear Ratio, $G$ & 8.2 \\
Air-gap length (inner and outer) & $2.5 \mathrm{~mm}$ \\
Active length & $260 \mathrm{~mm}$ \\
Outside diameter & $370 \mathrm{~mm}$ \\
Speed in high-speed rotor & $975 \mathrm{rpm}$ \\
Speed in low-speed rotor & $119 \mathrm{rpm}$ \\
Remanence of permanent magnets & $1.29 \mathrm{~T}$ \\
Grade of ferromagnetic poles & M330-50A \\
Rotor bars & Solid Copper \\
\hline
\end{tabular}

As explained in the introduction, the modulated flux is a crucial factor because of magnetic coupling and torque production. In Fig. 2, it can be seen that there is leakage flux which needs to be analyzed carefully. An improvement in the air-gap flux density does not ensure better modulated flux density. It might lead to unwanted harmonics in the modulated flux and reduce efficiency of the MG.

In addition, its effects on cogging torque and torque ripple are important points to be considered. The modulated airgap flux density is analyzed as function of magnet span to analyze flux leakage and to optimize magnet volume without reducing the harmonic component of modulated flux density. Fig 3 shows the effects of reducing magnet span by up to $30 \%$, in terms of reduction in the harmonic component of the modulated field in the outer airgap due to inner magnet and modulating ring. Fig. 4 shows the harmonic spectrum of modulated flux density in the conventional MG and the proposed MG. Simulation results show that up to 5 percent reduction in the magnetspan does not significantly reduce the modulated flux.

Although overload protection is one of the significant characteristics of magnetic gearboxes, the continuous operation of MGs is also vital. The proposed gearbox takes advantage of the 5 percent reduction in magnet volume to employ cage rotor bars in slots to increase the torque at overload conditions. The rotor bars passively contribute to reduce pole-slipping problems and try to synchronize the magnetic coupling at overload condition.

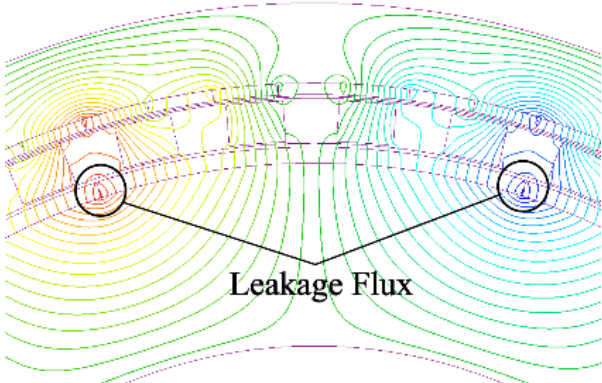

Fig. 2. Leakage flux in the inner rotor

In Fig. 4, some harmonics are created besides $36^{\text {th }}$ component which refers to the number of outer magneticpoles. These harmonics cause torque ripples in the MG. The comparison of some harmonic components is given in Table II.

TABLE II: Parameters of the magnetic gearbox.

\begin{tabular}{|c|c|c|c|c|c|c|}
\hline & 6 th & 15 th & 16th & 25th & 26th & 46th \\
\hline Conv. & 0.017 & 0.104 & 0.035 & 0.031 & 0.063 & 0.052 \\
\hline Prop. & 0.014 & 0.101 & 0.032 & 0.028 & 0.061 & 0.052 \\
\hline
\end{tabular}

The harmonic components of modulated flux density in both gearboxes are compared. It is observed that the harmonics which cause torque ripple are slightly lower in the proposed MG.

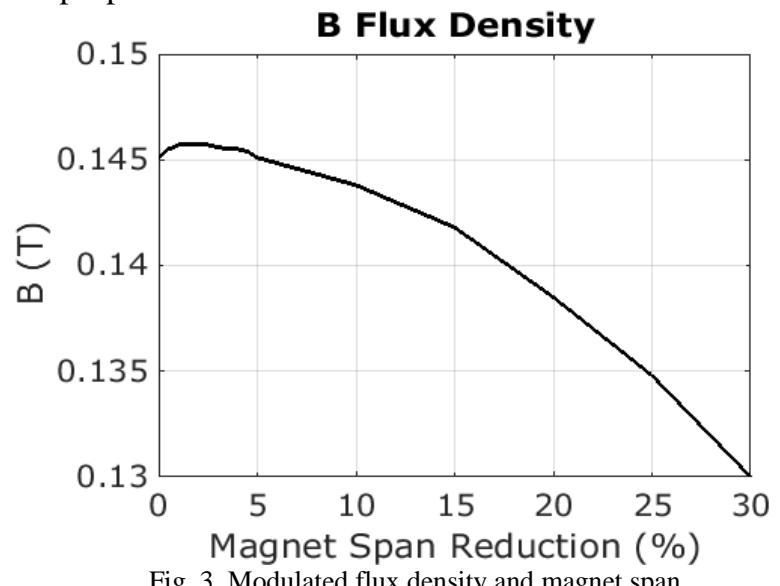

Fig. 3. Modulated flux density and magnet span

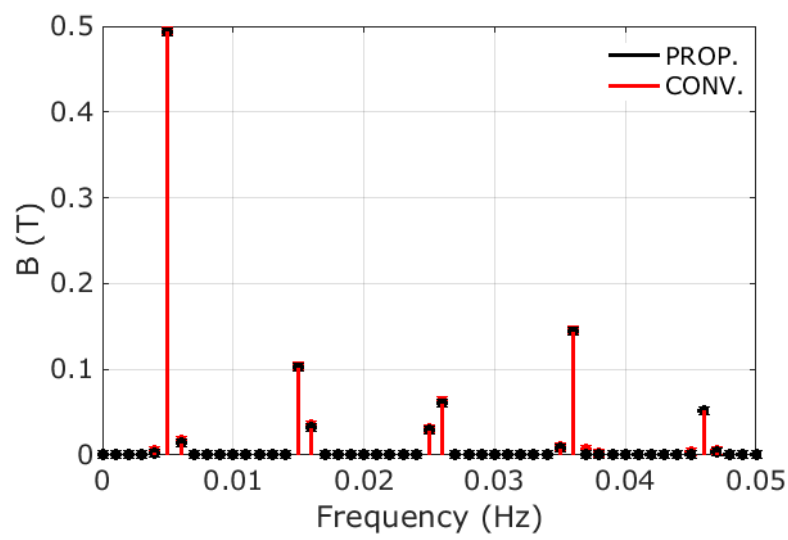

Fig.4. Comparison of harmonic components of modulated flux density in conventional and proposed MG 


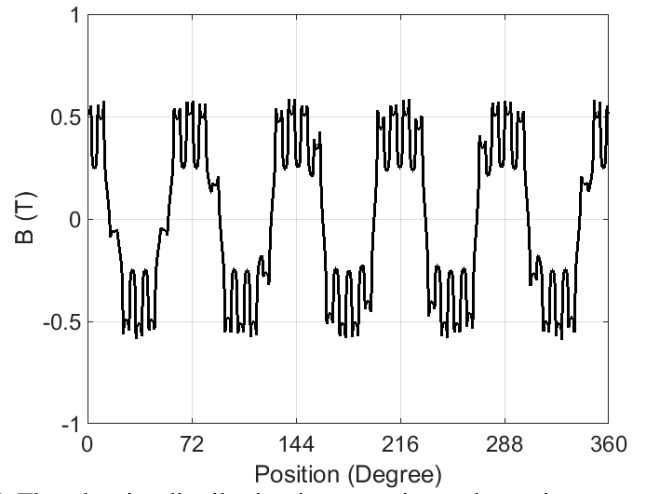

Fig. 5. Flux density distribution in outer airgap due to inner magnet and modulating ring

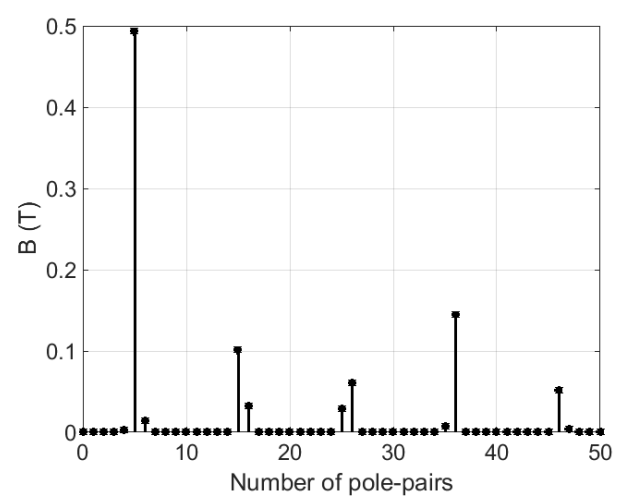

Fig. 6. Harmonic spectrum of flux density distribution in outer airgap due to inner magnet and modulating ring

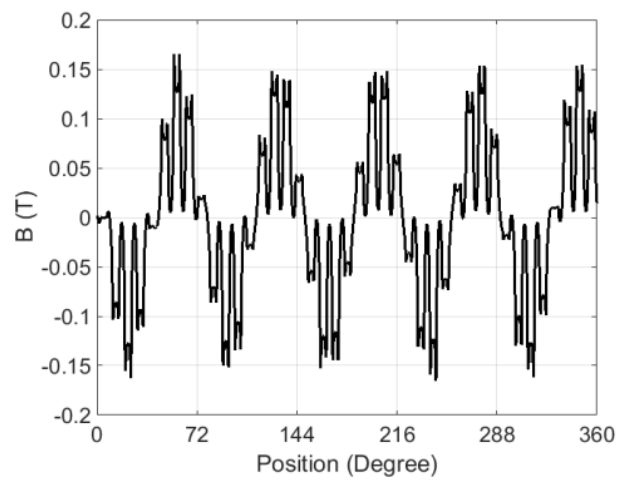

Fig. 7. Flux density distribution in inner airgap due to outer magnet and modulating ring

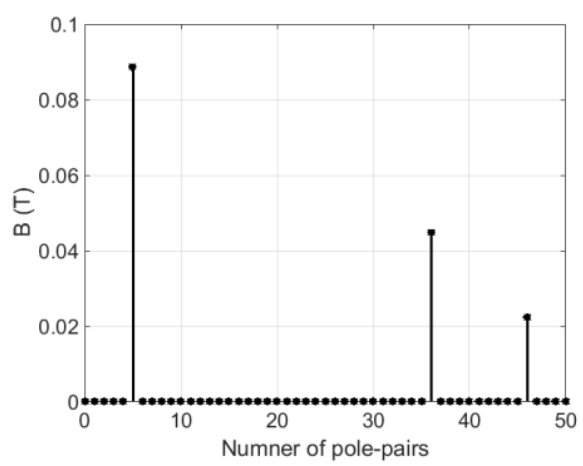

Fig. 8. Harmonic spectrum of flux density distribution in inner airgap due to outer magnet and modulating ring
Fig. 5, and Fig. 6 demonstrate the magnetic flux density wave form in the outer airgap due to inner magnet and modulating ring, and its harmonic components, respectively. The $5^{\text {th }}$ component is produced by the inner magnetic pole-pairs and $36^{\text {th }}$ component is produced by inner magnetic pole-pairs and the modulating ring. Similarly, Fig. 7 and Fig. 8 show the magnetic flux density wave form in the inner airgap due to outer magnet and modulating ring, and its harmonic components, respectively. In Fig. 8, the $5^{\text {th }}$ harmonic component is the modulated component due to outer magnetic pole-pairs and modulating ring, and $36^{\text {th }}$ component is the actual magnetic field due to 36 magnetic pole-pairs. To verify the working principle of the MG, it is important to see the matching between different numbers of magnetic pole-pairs due to the modulating ring. Therefore, modulating ring creates matching pole numbers between the outer and inner magnetic field, and so the two rotors can operate to produce stable torque.

\section{Simulation Results}

The performance evaluation of both conventional and proposed gearboxes is done by Finite Element Analysis (FEA). In this section, the static torque characteristics, noload and maximum load analyses and overload behaviors of the proposed MG are detailed. The results are compared with a conventional MG.

\section{A. STATIC TORQUE}

The static torque is obtained by rotating the inner rotor at rated speed while the modulating ring is stationary. Fig. 9 shows the static torque of the conventional and proposed MG at various values of torque angle. When the MG is under no-load condition, the equilibrium point will be at no-load point. In case of a torque demand exceeding the maximum load point (overload condition), the equilibrium point goes beyond the maximum point, and the MG will desynchronise and slip. In normal operation, the coupling rotates synchronously and the cage bars are not in operation as there is no continuous slip and so no induced EMF in the cage. In case of overload, the magnetic coupling will not be able to carry the load and the rotor will slip. Therefore, current will be induced in cage rotor bars, which will produce a magnetic field that attempts to align the slipping rotor to the synchronous speed, increasing the output torque in the slip condition.

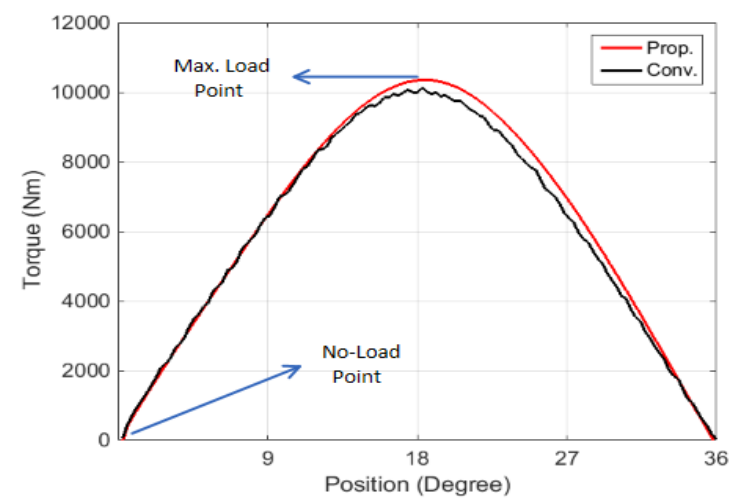

Fig. 9. Static torque characteristic 


\section{B. TORQUE CHARACTERISTICS}

In no-load operation, the MG runs at zero equilibrium point. Fig. 10 and Fig. 11 show the input torque and output torque of proposed and conventional $\mathrm{MG}$, respectively. It is clearly seen that proposed gearbox has less torque ripple than the conventional MG. Table II proves that due to reduction in harmonics which cause torque ripple, the torque gives smoother response in the proposed MG. The improvement is due to reducing harmonics that cause ripples in torque response, which can clearly be seen in the input and output torque.

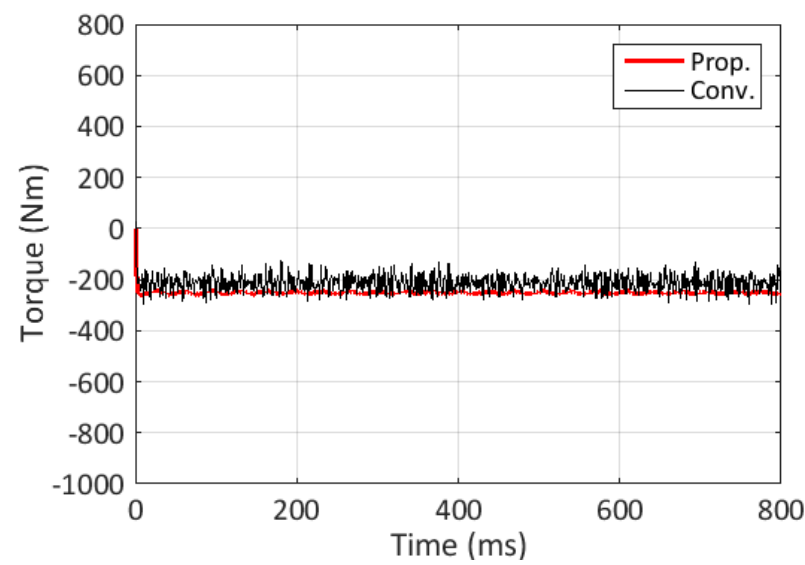

Fig. 10. Input torque

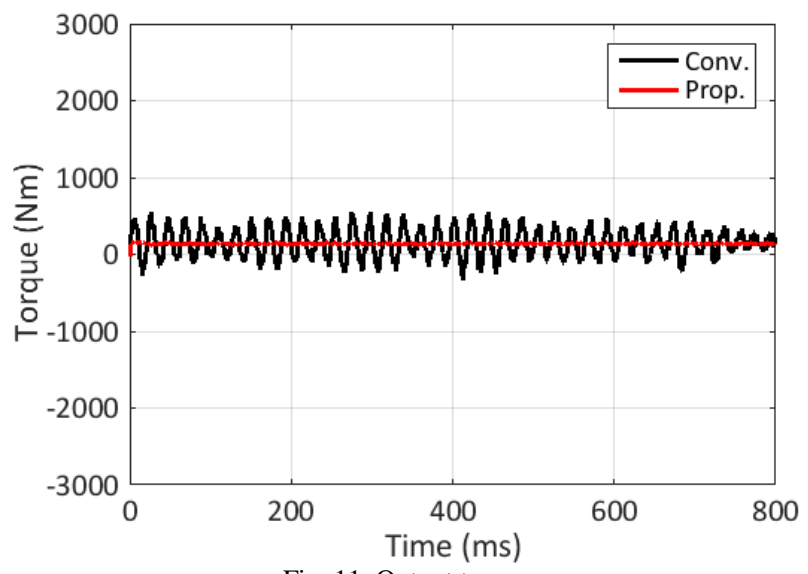

Fig. 11. Output torque

In the next simulation, the torque angle is set to the maximum point. The resulting input and output torque responses of both conventional and proposed gearboxes are shown in Fig 12. and Fig 13. Similarly, the proposed MG shows less ripple at maximum torque point due to a reduction of harmonics as seen in Table II.

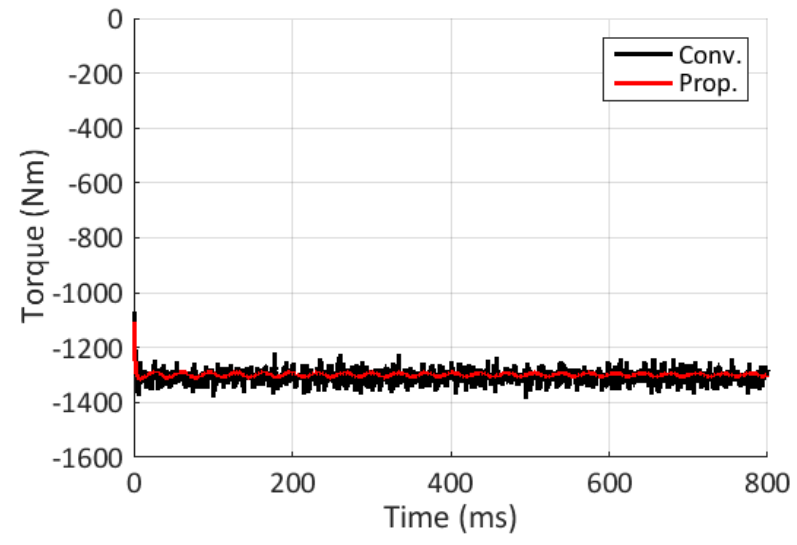

Fig. 12. Input torque

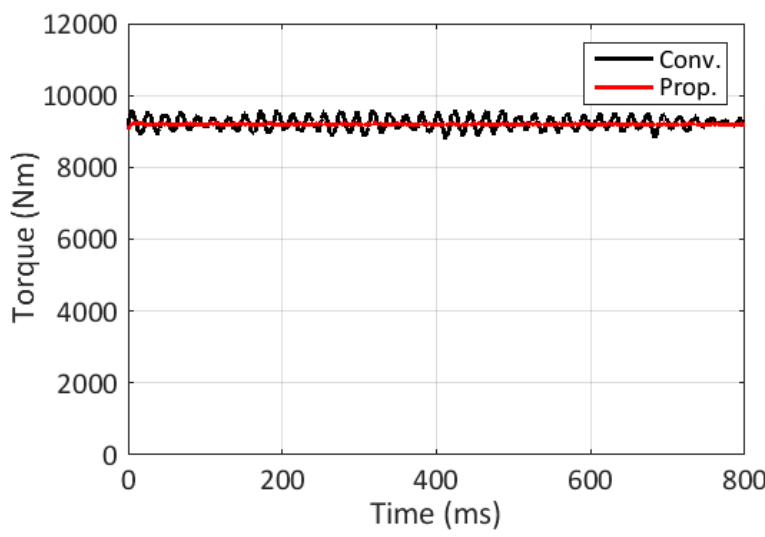

Fig. 13. Output torque

\section{A. OVERLOAD PERFORMANCE}

In this section, torque response and behavior of rotor bars are observed under overload conditions and the results are compared with the conventional MG. As is explained in the static torque section, the torque angle changes with load torque. However, when the load torque exceeds the maximum torque that the MG can produce, the coupling loses its connection and the rotor slips. In this case, current will be induced in the rotor bars. To see the torque contribution of cage rotor bars at the overload condition, both gearboxes are over-loaded to $110 \%$ of their maximum capacity at rated speed and their torque responses are observed. Fig. 14 shows the torque response under overload condition, while Fig. 15 shows the slip and induced current in one of the cage bars. The torque contribution of the cage rotor bars can clearly be seen in Fig. 14. 


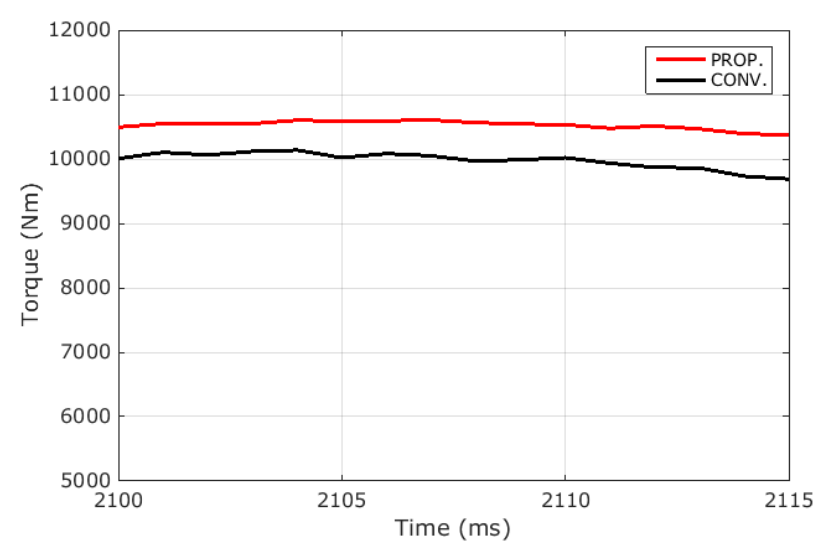

Fig. 14: The torque response under overload condition

The current is induced once there is slip and its contribution will be added to the overall torque response. It is clearly seen that the proposed gear can produce more torque than the conventional gearbox during overload with 5 percent less magnets. The output torque is increased by 600 $\mathrm{Nm}$ meaning that the proposed gearbox increases the torque density from $89.4 \mathrm{kNm} / \mathrm{m}^{3}$ to $94.8 \mathrm{kNm} / \mathrm{m}^{3}$ with $5 \%$ less magnet volume and with cage rotor bars.

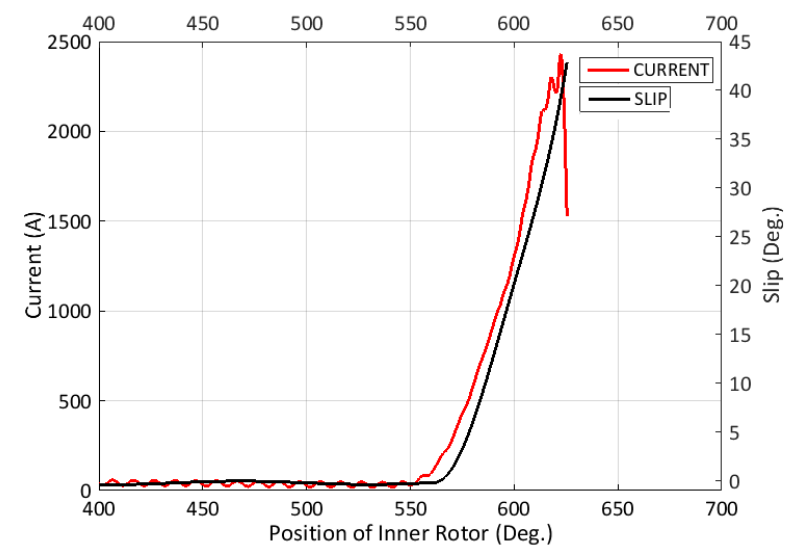

Fig. 15. Bar current and slip response

\section{CONCLUSION}

In this paper, a new high-speed rotor configuration in MG has been introduced, in which cage rotor bars are used. The flux density distribution has been analyzed as function of magnet span to see the reduction in modulated flux. The proposed MG presents 5 percent less magnet volume and produce higher torque in overload condition by comparison with the conventional MG.

\section{REFERENCES}

[1] K. Atallah, J. Rens, S. Mezani, and D. Howe, "A novel pseudo direct drive brushless permanent magnet machine," IEEE Trans. Magn., vol. 44, no. 11 , pp. 4349-4352, Nov. 2008

[2] R. Montague, C. Bingham and K. Atallah "Servo control of magnetic gears", IEEE/ASME Trans. Mechatronics, vol. PP, no. 99, pp. $1-102011$

[3] T. O. Andersen, F. T. Jorgensen, and O. Nielsen, "Development of a high-performance magnetic gear," IEEE Transactions on Industry Applications, Vol. 41, No. 3, pp. 764-770, 2005.
[4] E. Gouda, S. Mezani, L. Baghli, A. Rezzoug, "Comparative study between mechanical and magnetic planetary gears", IEEE Trans. Magn., vol. 47, no. 2, pp. 439-450, Feb. 2011.

[5] K. Tsurumoto and S. Kikuchi, "A New Magnetic Gear Using Permanent Magnet," IEEE Trans. on Magn., MAG-23, pp.36223624, 1987.

[6] K. Atallah and D. Howe, "A novel high-performance magnetic gear,” IEEE Trans. Magn., vol. 37, no. 4, pp. 2844-2846, Jul. 2001.

[7] G. Dajaku, D. Gerling, "Determination of air-gap flux density due to magnets using the new analytical model", Electrical Machines (ICEM) 2010 XIX International Conference on, 2010.

[8] L. Jian and K. T. Chau, "A coaxial magnetic gear with Halbach permanent magnet arrays," IEEE Trans. Energy Conv., to be published

[9] K. Atallah, S.D. Calverley, D. Howe, "Design analysis and realization of a high-performance magnetic gear", Inst. Electr. Eng. Proc. Electr. Power Appl., vol. 151, no. 2, pp. 135-143, Mar. 2004.

[10] T. Lubin, S. Mezani, A. Rezzoug, "Analytical computation of the magnetic field distribution in a magnetic gear", IEEE Trans. Magn., vol. 46, no. 7, pp. 2611-2621, Jul. 2010.

[11] Z. Q. Zhu, D. Howe, "Instantaneous magnetic-field distribution in brushless permanent-magnet dc motor part III: Effect of slotting", IEEE Trans. Magn., vol. 29, no. 1, pp. 143-151, Jan. 1993. 